\title{
Cost Variability of Suggested Generic Treatment Alternatives Under the Medicare Part D Benefit
}

\author{
Rajul A. Patel, PharmD, PhD; Mark P. Walberg, PharmD, PhD; Emily Tong, PharmD; \\ Florence Tan, PharmD; Ashley E. Rummel, PharmD; Joseph A. Woelfel, RPh, PhD; \\ Sian M. Carr-Lopez, PharmD; and Suzanne M. Galal, PharmD
}

\begin{abstract}
BACKGROUND: The substitution of generic treatment alternatives for brand-name drugs is a strategy that can help lower Medicare beneficiary out-of-pocket costs. Beginning in 2011, Medicare beneficiaries reaching the coverage gap received a $50 \%$ discount on the full drug cost of brandname medications and a $7 \%$ discount on generic medications filled during the gap. This discount will increase until 2020, when beneficiaries will be responsible for $25 \%$ of total drug costs during the coverage gap.

OBJECTIVE: To examine the cost variability of brand and generic drugs within 4 therapeutic classes before and during the coverage gap for each 2011 California stand-alone prescription drug plan (PDP) and prospective coverage gap costs in 2020 to determine the effects on beneficiary out-ofpocket drug costs.
\end{abstract}

METHODS: Equivalent doses of brand and generic drugs in the following 4 pharmacological classes were examined: angiotensin II receptor blockers (ARBs), bisphosphonates, HMG-CoA reductase inhibitors (statins), and proton pump inhibitors (PPIs). The full drug cost and patient copay/coinsurance amounts during initial coverage and the coverage gap of each drug was recorded based on information retrieved from the Medicare website. These drug cost data were recorded for 28 California PDPs.

RESULTS: The highest cost difference between a brand medication and a Centers for Medicare \& Medicaid Services (CMS)-suggested generic treatment alternative varied between $\$ 110.53$ and $\$ 195.49$ at full cost and between $\$ 51.37$ and $\$ 82.35$ in the coverage gap. The lowest cost difference varied between $\$ 38.45$ and $\$ 76.93$ at full cost and between $-\$ 4.11$ and $\$ 18.52$ during the gap.

CONCLUSION: Medicare beneficiaries can realize significant out-of-pocket cost savings for their drugs by taking CMS-suggested generic treatment alternatives. However, due to larger discounts on brand medications made available through recent changes reducing the coverage gap, the potential dollar savings by taking suggested generic treatment alternatives during the gap is less compelling and will decrease as subsidies increase.

J Manag Care Pharm. 2014;20(3):283-90

Copyright $\odot 2014$, Academy of Managed Care Pharmacy. All rights reserved.

\section{What is already known about this subject}

- In accordance with the Patient Protection and Affordable Care Act signed in March 2010, Medicare beneficiaries will receive a graduated manufacturer-paid point-of-sale discount on formulary covered brand-name medications when filled during the coverage gap effective in 2011.
- Additionally, a beneficiary's Part D plan will also provide a discount for generic medications filled during the coverage gap effective in 2011.

- The coverage gap discount for both brand-name and generic medications will increase until 2020, when beneficiaries will be responsible for $25 \%$ of total drug costs during the coverage gap.

- Angiotensin II receptor blockers (ARBs), bisphosphonates, HMGCoA reductase inhibitors (statins), and proton pump inhibitors (PPIs) are 4 highly utilized drug classes by Medicare beneficiaries; each of these classes contain therapeutically equivalent brand and generic medications.

\section{What this study adds}

- The out-of-pocket cost variability of 4 drug classes (ARBs, bisphosphonates, statins, and PPIs) during initial coverage and the coverage gap was summarized for each stand-alone prescription drug plan available in California in 2011.

- With only 1 exception, out-of-pocket costs for generic medications remained less expensive alternatives to brand-name medications, despite a larger subsidy for brand-name medications during the coverage gap in 2011.

- We demonstrated that beneficiary costs may decrease in the coverage gap from the original Medicare coverage level, while placing more financial pressure on the plans to incentivize patients.

$\mathrm{R}$ esearch has established that a relationship exists between an individual's out-of-pocket (OOP) medication costs and drug utilization..$^{1-4}$ As OOP drug costs increase, individuals are less likely to visit pharmacies and increasingly likely to delay or forgo filling their medications. ${ }^{1-4}$ The federal government's introduction of Medicare Part D provided seniors aged 65 years and older and other eligible beneficiaries a unique opportunity to enroll in a prescription drug plan. Following introduction of the Part $\mathrm{D}$ benefit in 2006 , beneficiary drug utilization increased by $7 \%$, and OOP costs decreased by $16 \%$, a testament to the program's success. ${ }^{5}$

While Part D offsets prescription medication costs for many, shortcomings remain in this federally directed program. Since its inception in 2006, most Part D plans have had a period during which the beneficiary is solely responsible for the majority of prescription drug costs. This is called the coverage 


\section{TABLE 1 Beneficiary Cost Responsibilities in the Gap ${ }^{14}$}

\begin{tabular}{l|c|c}
\hline Year & Brand Drugs (\%) & Generic Drugs (\%) \\
\hline $2006-2009$ & 100 & 100 \\
\hline 2010 & \multicolumn{2}{|c|}{$100 \%$ with $\$ 250$ rebate } \\
\hline 2011 & 50 & 93 \\
\hline 2012 & 50 & 86 \\
\hline 2013 & 47.5 & 79 \\
\hline 2014 & 47.5 & 72 \\
\hline 2015 & 45 & 65 \\
\hline 2016 & 45 & 58 \\
\hline 2017 & 40 & 51 \\
\hline 2018 & 35 & 44 \\
\hline 2019 & 30 & 37 \\
\hline 2020 & 25 & 25
\end{tabular}

gap and is commonly referred to as the "donut hole." The coverage gap starts after beneficiaries and their plans have spent a predetermined amount on formulary covered drugs. ${ }^{6}$ Prior to 2010 , most beneficiaries were required to pay $100 \%$ of their prescription medication costs when filled during the donut hole. ${ }^{7}$ Higher OOP medication costs can be a major problem for those beneficiaries with limited income and resources. ${ }^{1,3,4}$ Moreover, research has shown that a beneficiary's inability to afford medications during the donut hole can be linked to such problematic medication behaviors as skipping doses, delaying refills, using medications less frequently, stopping medications, or going without certain basic necessities (e.g., food or rent) in order to afford medications. ${ }^{1}$ Medication adherence has been shown to be negatively correlated with patients' OOP costs..$^{2-4}$

Taira et al. (2006) reported that medication adherence decreased as drug copayments increased among patients with hypertension taking at least 1 antihypertensive medication. ${ }^{2}$ In this study, patients were deemed to be adherent to their antihypertensive medications if their medication possession ratio was $>80 \%$. Using this definition of adherence, the odds ratio (OR) for adherence was 0.76 with a $\$ 5$ copayment; however, with higher copayments (ranging from \$20-\$165), the OR for adherence dropped to 0.48 . Results suggested that the copayment amount is a strong predictor of patient adherence. ${ }^{2}$ The same pattern emerged with respect to HMG-CoA reductase inhibitors (statins) - lower patient copayments were positively correlated with higher levels of medication adherence. ${ }^{3}$ A $\$ 10$ increase in copayments for statins was associated with a 1.8\% reduction in adherence for new users and a 3\% reduction in adherence for continuing users. ${ }^{3}$ This finding suggests adoption of lower copayments may increase medication adherence and should therefore be considered by plan administrators. ${ }^{3}$ Another study found that medication adherence in patients decreased following a $\$ 5$ systemwide increase in copayments at Veterans Affairs medical centers. ${ }^{4}$ The long-term effect of this nominal copayment change was a decrease in veterans' adherence to oral hypoglycemic agents by $10.3 \%$, antihypertensive agents by $5.4 \%$, and statins by $1.9 \% .{ }^{4}$ Clearly, reduced adherence to long-term medications increases the likelihood of significant and costly clinical events that ultimately increase total health care costs..$^{2-4}$

While there is little, if anything, beneficiaries can do to lower manufacturer-set medication prices, increasing prescriber awareness of medication costs may be an integral step in decreasing cost-related drug nonadherence. Prescriber knowledge regarding medication costs was examined in a survey-based study among 210 general practitioners. Of those surveyed, $43 \%$ were found to have limited, if any, knowledge of drug costs. ${ }^{8}$ Furthermore, the study suggested that prescribers with inaccurate drug cost estimates were less likely than other prescribers to exercise therapeutic substitution. ${ }^{8}$

A lack of effective communication also exists between prescribers and patients with regards to concerns of medication affordability. A survey of 17,569 Medicare beneficiaries in 2003 revealed that $26.3 \%$ had cost-related medication nonadherence. ${ }^{9}$ Of those, $61 \%$ expressed concerns about their medication costs to their physicians, and only $38.1 \%$ were switched to a cheaper alternative by their physicians. ${ }^{9}$ In a nationwide survey of adults with chronic illnesses who admitted to costrelated medication underutilization, two-thirds claimed never discussing planned cost-related underuse with their physicians, and over half did not believe their providers could help. ${ }^{10}$ Even when patients discussed medication costs with their physicians, fewer than 1 in 3 said their physicians made any attempt to address their cost-related concerns. ${ }^{10}$

Another aspect to this issue involves patients' willingness to pay more for brand-name medications. A survey of members in a large managed care organization in the western United States was conducted, and participants with a chronic disease (i.e., hypertension, diabetes, dyslipidemia, arthritis, or gastroesophageal reflux disease) were asked if they would be willing to pay extra for a brand-name medication. Half of the respondents were willing to pay extra, even if a generic equivalent was available. ${ }^{11}$ However, there appeared to be a financial threshold, as a majority indicated reluctance to pay more than an additional $\$ 10$ per month for a brand-name medication, when a less expensive alternative was available. ${ }^{11}$

While some patients may desire brand-name drugs, OOP costs can be a contributing factor to adherence. Claims data for new prescriptions of generic or brand-only drug therapy were analyzed for medication adherence among patients with specific medical conditions. Generic drugs were associated with significantly greater adherence than brand-name drugs in patients with hypercholesterolemia (62\% vs. 53\%) but surprisingly significantly lower adherence in patients with hypertension ( $47 \%$ vs. $59 \%)^{12}$ No significant difference in adherence rates between generic and brand medications was found for the other investigated conditions, including seizure disorders, hypothyroidism, and type 2 diabetes. ${ }^{12}$ The study authors did 
TABLE 2 ARBs: Average (SD) Costs of Brand-Name Medications and Suggested Generic Treatment Alternatives Under 2011 California PDPs

\begin{tabular}{|c|c|c|c|c|c|c|c|c|c|}
\hline \multirow[b]{2}{*}{ Druga } & & \multicolumn{8}{|c|}{$\downarrow$ in SBP/DBP $(\mathrm{mm} \mathrm{Hg})^{b}$} \\
\hline & & \multicolumn{2}{|c|}{$7-8 / 4-5$} & \multicolumn{2}{|c|}{$8-10 / 5-6$} & \multicolumn{2}{|c|}{$10-12 / 6-7$} & \multicolumn{2}{|c|}{$12-13 / 7-8$} \\
\hline \multirow{5}{*}{$\begin{array}{l}\text { Candesartanc } \\
(\mathrm{n}=7)\end{array}$} & Dose & \multicolumn{2}{|c|}{$4 \mathrm{mg}$} & \multicolumn{2}{|c|}{$8 \mathrm{mg}$} & \multicolumn{2}{|c|}{$16 \mathrm{mg}$} & \multicolumn{2}{|c|}{$32 \mathrm{mg}$} \\
\hline & Total drug cost $(\$)$ & 71.97 & (4.19) & 71.97 & (4.19) & 71.97 & $(4.19)$ & 71.97 & (4.19) \\
\hline & Initial coverage $(\$)$ & 57.57 & $(22.15)$ & 57.57 & $(22.15)$ & 57.57 & $(22.15)$ & 57.57 & $(22.15)$ \\
\hline & Coverage gap (\$) & 36.95 & $(2.04)$ & 36.95 & $(2.04)$ & 36.95 & $(2.04)$ & 36.95 & $(2.04)$ \\
\hline & 2020 gap $(\$)$ & 17.99 & $(1.05)$ & 17.99 & $(1.05)$ & 17.99 & $(1.05)$ & 17.99 & $(1.05)$ \\
\hline \multirow{5}{*}{$\begin{array}{l}\text { Eprosartanc } \\
(n=4)\end{array}$} & Dose & & & \multicolumn{2}{|c|}{$400 \mathrm{mg}$} & \multicolumn{2}{|c|}{$600 \mathrm{mg}$} & & \\
\hline & Total drug cost $(\$)$ & & & 90.85 & $(5.07)$ & 106.10 & $(5.87)$ & & \\
\hline & Initial coverage $(\$)$ & & & 83.88 & $(4.66)$ & 83.88 & $(4.66)$ & & \\
\hline & Coverage gap (\$) & & & 46.21 & $(2.68)$ & 53.80 & (3.08) & & \\
\hline & 2020 gap $(\$)$ & & & 22.71 & $(1.27)$ & 26.53 & $(1.47)$ & & \\
\hline \multirow{5}{*}{$\begin{array}{l}\text { Irbesartanc } \\
(\mathrm{n}=10)\end{array}$} & Dose & & & \multicolumn{2}{|c|}{$75 \mathrm{mg}$} & \multicolumn{2}{|c|}{$150 \mathrm{mg}$} & \multicolumn{2}{|c|}{$300 \mathrm{mg}$} \\
\hline & Total drug cost $(\$)$ & & & 78.06 & $(3.83)$ & 82.08 & $(4.04)$ & 98.24 & $(4.87)$ \\
\hline & Initial coverage $(\$)$ & & & 39.32 & $(24.25)$ & 40.09 & $(24.69)$ & 41.74 & $(23.81)$ \\
\hline & Coverage gap (\$) & & & 40.00 & (1.93) & 42.00 & $(2.03)$ & 50.09 & $(2.42)$ \\
\hline & 2020 gap $(\$)$ & & & 19.52 & $(0.96)$ & 20.52 & $(1.01)$ & 24.56 & $(1.22)$ \\
\hline \multirow{5}{*}{$\begin{array}{l}\text { Losartan } \\
(25 \mathrm{mg}: \mathrm{n}=26 ; \\
50 \mathrm{mg} \text { and } \\
100 \mathrm{mg}: \mathrm{n}=27)\end{array}$} & Dose & \multicolumn{2}{|c|}{$25 \mathrm{mg}$} & \multicolumn{2}{|c|}{$50 \mathrm{mg}$} & \multicolumn{2}{|c|}{$100 \mathrm{mg}$} & & \\
\hline & Total drug cost $(\$)$ & 20.30 & $(11.84)$ & 25.36 & (15.31) & 33.60 & $(21.86)$ & & \\
\hline & Initial coverage $(\$)$ & 6.23 & $(5.17)$ & 6.36 & $(5.67)$ & 6.75 & $(6.10)$ & & \\
\hline & Coverage gap $(\$)$ & 17.34 & (11.33) & 21.28 & $(14.80)$ & 28.12 & $(21.09)$ & & \\
\hline & 2020 gap $(\$)$ & 5.08 & $(2.96)$ & 6.34 & (3.83) & 8.40 & $(5.46)$ & & \\
\hline \multirow{5}{*}{$\begin{array}{l}\text { Olmesartanc } \\
(\mathrm{n}=11)\end{array}$} & Dose & & & \multicolumn{2}{|c|}{$5 \mathrm{mg}$} & \multicolumn{2}{|c|}{$20 \mathrm{mg}$} & \multicolumn{2}{|c|}{$40 \mathrm{mg}$} \\
\hline & Total drug cost $(\$)$ & & & 67.23 & $(3.08)$ & 81.74 & $(3.78)$ & 113.04 & $(5.32)$ \\
\hline & Initial coverage $(\$)$ & & & 38.29 & $(16.16)$ & 42.68 & $(19.77)$ & 49.96 & $(19.53)$ \\
\hline & Coverage gap $(\$)$ & & & 34.64 & $(1.58)$ & 41.63 & $(2.43)$ & 57.55 & $(2.62)$ \\
\hline & 2020 gap $(\$)$ & & & 16.81 & $(0.77)$ & 20.43 & $(0.95)$ & 28.26 & (1.33) \\
\hline & Dose & & & 20 & & 40 & & 80 & ng \\
\hline & Total drug cost $(\$)$ & & & 99.37 & $(4.60)$ & 99.37 & $(4.60)$ & 99.37 & $(4.60)$ \\
\hline $\begin{array}{l}\text { lelmisartanc } \\
(\mathrm{n}=18)\end{array}$ & Initial coverage $(\$)$ & & & 43.53 & $(22.81)$ & 43.53 & $(22.81)$ & 43.53 & $(22.81)$ \\
\hline & Coverage gap (\$) & & & 50.57 & $(2.62)$ & 50.57 & $(2.62)$ & 50.57 & $(2.62)$ \\
\hline & 2020 gap $(\$)$ & & & 24.84 & $(1.15)$ & 24.84 & (1.15) & 24.84 & $(1.15)$ \\
\hline Valsartanc & Dose & & & 80 & & 160 & $\mathrm{ng}$ & 320 & $\mathrm{mg}$ \\
\hline (40 mg and & Total drug cost $(\$)$ & 130.80 & $(23.91)$ & 81.88 & $(3.34)$ & 87.89 & $(3.58)$ & 110.61 & $(4.41)$ \\
\hline 320 mg: $\mathrm{n}=27$ & Initial coverage $(\$)$ & 42.71 & $(16.03)$ & 35.76 & $(13.16)$ & 37.46 & $(14.25)$ & 40.57 & (16.29) \\
\hline $80 \mathrm{mg}$ and & Coverage gap (\$) & 68.71 & $(2.94)$ & 41.89 & (1.98) & 44.89 & (2.09) & 56.26 & $(2.46)$ \\
\hline 160 mg: $n=26)$ & 2020 gap $(\$)$ & 32.70 & $(5.98)$ & 20.47 & $(0.84)$ & 21.97 & $(0.90)$ & 27.65 & $(1.10)$ \\
\hline
\end{tabular}

$a_{n}$ indicates number of PDPs with medication on plan formulary.

bBlood pressure decrease based on Medicare Plan Finder Tool equivalency tables and package insert data.

'Indicates drug was available brand only at the time of data pull.

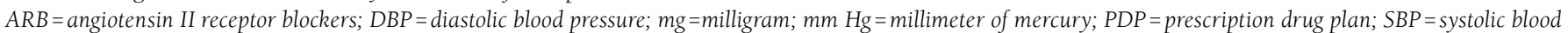
pressure; $S D=$ standard deviation.

not identify any concrete reasons for these results but did find that $\$ 0$ copayment amounts were related to increased medication adherence regardless of the individual's medical condition or whether the medication in question was generic or brand. ${ }^{12}$ These findings may indicate that any OOP costs may decrease adherence.

Starting in 2011, in accordance with the Patient Protection and Affordable Care Act, Medicare beneficiaries received a 50\% manufacturer-paid point-of-sale copay discount off the total cost of the drug on formulary covered brand-name medications when filled during the coverage gap. ${ }^{13}$ Additionally, in 2011, a beneficiary's Part D plan discounted generic medications by $7 \%$ of the total drug cost, when filled during the coverage gap. ${ }^{6}$ To date, no studies have examined the cost difference between brand-name medications and suggested generic treatment alternatives during the coverage gap under Part D. This coverage gap discount is set to increase until 2020, when beneficiaries will be responsible for $25 \%$ of total drug costs for both brand and generic medications (Table 1). Manufacturers will still be responsible for $50 \%$, and the Part D plan will then 
Cost Variability of Suggested Generic Treatment Alternatives Under the Medicare Part D Benefit

\section{TABLE 3 Bisphosphonates: Average (SD) Costs of Brand-Name Medications and} Suggested Generic Treatment Alternatives Under 2011 California PDPs

\begin{tabular}{|c|c|c|c|c|c|c|}
\hline \multirow[b]{2}{*}{$\underline{\text { Druga }^{a}}$} & & \multicolumn{5}{|c|}{ Regimen } \\
\hline & & \multicolumn{2}{|c|}{ Daily } & \multicolumn{2}{|c|}{ Weekly } & Monthly \\
\hline \multirow{5}{*}{$\begin{array}{l}\text { Alendronate } \\
(5 \mathrm{mg}, 35 \mathrm{mg} \text {, } \\
70 \mathrm{mg}: \mathrm{n}=28 \\
10 \mathrm{mg}: \mathrm{n}=26)\end{array}$} & Dose (quantity) & $5 \mathrm{mg}(30)$ & $10 \mathrm{mg}(30)$ & $35 \mathrm{mg}(4)$ & $70 \mathrm{mg} \mathrm{(4)}$ & \\
\hline & Total drug cost $(\$)$ & $28.60 \quad(18.48)$ & $25.16 \quad(16.06)$ & $18.76(\$ 15.80)$ & $18.39 \quad(14.39)$ & \\
\hline & Initial coverage $(\$)$ & $4.95 \quad(3.33)$ & $5.15 \quad(2.99)$ & $4.54 \quad(\$ 3.21)$ & $4.14 \quad(2.72)$ & \\
\hline & Coverage gap (\$) & $21.20 \quad(18.32)$ & $17.82 \quad(15.22)$ & $15.50(\$ 15.53)$ & $14.39 \quad(14.16)$ & \\
\hline & 2020 gap $(\$)$ & $7.15 \quad(4.62)$ & $6.29 \quad(4.01)$ & $4.69 \quad(\$ 3.95)$ & $4.60 \quad(3.60)$ & \\
\hline \multirow{5}{*}{$\begin{array}{l}\text { Risedronate } \\
(\mathrm{n}=16)\end{array}$} & Dose (quantity) & $5 \mathrm{mg}(30)$ & & $35 \mathrm{mg}(4)$ & & $150 \mathrm{mg}(1)$ \\
\hline & Total drug cost $(\$)$ & $114.47 \quad(3.93)$ & & $106.95 \quad(3.67)$ & & $115.70 \quad(3.97)$ \\
\hline & Initial coverage $(\$)$ & $61.29 \quad(23.37)$ & & $60.49 \quad(24.08)$ & & $61.42 \quad(23.26)$ \\
\hline & Coverage gap (\$) & $58.18 \quad(2.07)$ & & $54.41 \quad(1.95)$ & & $58.79 \quad(2.08)$ \\
\hline & 2020 gap $(\$)$ & $28.62 \quad(0.98)$ & & $26.74 \quad(0.92)$ & & $28.92 \quad(0.99)$ \\
\hline \multirow{5}{*}{$\begin{array}{l}\text { Ibandronate } \\
(\mathrm{n}=23)\end{array}$} & Dose (quantity) & & & & & $150 \mathrm{mg}(1)$ \\
\hline & Total drug cost $(\$)$ & & & & & $115.02 \quad(4.19)$ \\
\hline & Initial coverage $(\$)$ & & & & & $42.72 \quad(13.56)$ \\
\hline & Coverage gap (\$) & & & & & $58.51 \quad(2.51)$ \\
\hline & 2020 gap $(\$)$ & & & & & $28.76 \quad(1.05)$ \\
\hline
\end{tabular}

be responsible for the remaining $25 \%$ of total brand drug costs during the gap. ${ }^{14}$ This cost-sharing arrangement means that plans and beneficiaries will both have the same "skin in the game" during the coverage gap.

In this study, we analyzed beneficiary cost data of various suggested generic treatment alternatives. The objective of the present research was to determine cost disparities of brandname medications and equipotent suggested generic treatment alternatives during the coverage gap for drugs in 4 pharmacological classes: angiotensin II receptor blockers (ARBs), bisphosphonates, HMG-CoA reductase inhibitors (statins), and proton pump inhibitors (PPIs). Additionally, the future coverage gap drug costs in 2020 for beneficiaries and drug plans were estimated.

\section{Methods}

Four pharmacological drug classes (ARBs, bisphosphonates, statins, and PPIs) were chosen based on high utilization patterns by beneficiaries for treatment of common chronic conditions and the presence of suggested alternative brand-only and generic medications that existed within each class. Livalo (pitavastatin) was available in 2011 but did not have any cost data available on the Medicare website during the data collection period and was therefore excluded from the study. Dose equivalence for brand and generic drugs in all 4 classes was established using dose equivalency tables from the Medicare website and verified through examination of published literature and drug monographs.
The data collection period for this cross-sectional observational study commenced in January 2011 and ended in April 2011. Drugs from each of the 4 examined classes were entered into the Medicare Plan Finder Tool (available at https://www. medicare.gov/find-a-plan/questions/home.aspx). Alternative brand and generic medications were recorded from the Plan Finder Tool's "Lower Your Drug Costs" link available on the Plan Results page. This function is available for certain drugs that have alternative medications within the same drug class and allows users to view alternative equivalent doses of brand and generic medications within the same class and their respective costs under each plan. Next, the full drug cost and cost during the coverage gap as listed on the Medicare website was recorded for all 2011 California stand-alone prescription drug plans (PDPs). Although 33 PDPs were available in California in 2011, data from only 28 plans were available on the Medicare website during the data collection period. Plan drug costs were included in the analysis if the drug was on the plan's formulary.

The beneficiary's OOP cost during initial coverage and the coverage gap listed on the Medicare website for each analyzed medication was averaged across all available 2011 California PDPs that included it on their formularies. The estimated 2020 coverage gap cost for both beneficiaries and Part D plans was estimated by multiplying each drug's total cost by $25 \%$ and then averaging across all PDPs listing it as a formulary medication.

Descriptive statistics were used to summarize drug cost data. Data analyses were performed using SPSS, version 18.0 (Chicago, IL). 


\section{Results}

A total of 7 ARBs (candesartan, eprosartan, irbesartan, losartan, olmesartan, telmisartan, and valsartan); 3 bisphosphonates (alendronate, ibandronate, and risedronate); 6 PPIs (dexlansoprazole, esomeprazole, lansoprazole, omeprazole, pantoprazole, and rabeprazole); and 6 statins (atorvastatin, fluvastatin, lovastatin, pravastatin, rosuvastatin, and simvastatin) were examined. Tables 2-5 highlight the full initial coverage, 2011 coverage gap, and 2020 coverage gap costs (mean [SD]) of brand name and suggested generic treatment alternatives under the 28 available California PDPs in 2011.

Table 2 reveals that the costs of both candesartan and telmisartan were dose independent. Valsartan was unique in that the lowest and highest available strengths of the drug are more costly than other available strengths. During the coverage gap, brand-name drugs cost between $\$ 8.83$ and $\$ 51.37$ more than suggested generic treatment alternatives. Estimated 2020 coverage gap costs were lower than current copay amounts for all ARBs, except for lostartan (the only ARB available as a generic at the time of this study).

Cost data for orally administered bisphosphonates with daily, weekly, and monthly dosing regimens are presented in Table 3. Minimal cost differences were noted between different dosing regimens for each medication. Generically available alendronate 70 milligrams ( $\mathrm{mg}$ ) had the lowest OOP cost during the coverage gap in 2011 and as estimated for 2020. For all 3 dosing regimens, risedronate had higher average copay/ coinsurance amounts during the initial coverage level than during the 2011 or estimated 2020 coverage gap periods. No intravenous bisphosphonates were included, since these are billed to Medicare Part B, not Part D.

Equipotent doses of PPIs can be found in Table 4. The total drug cost difference between brands and suggested generic treatment alternatives ranged from $\$ 41.91$ to $\$ 195.49$. During the 2011 donut hole, the lowest cost brand-name drug (Dexilant, or dexlansoprazole, $30 \mathrm{mg}$, average [SD] coinsurance cost of $\$ 65.43$ [\$2.28]) was actually less expensive than the highest priced generic alternative (lansoprazole $15 \mathrm{mg}$, average [SD] coinsurance cost of \$69.54 [\$21.79]). This scenario was found to be true with the higher doses of Dexilant (dexlansoprazole) $60 \mathrm{mg}$ and lansoprazole $30 \mathrm{mg}$, as well. For all PPIs (except rabeprazole), the drug cost or copay/coinsurance amounts were similar or identical between the different strengths

Table 5 highlights cost differences for brand and generic statins. The full drug cost of statins is largely independent of dose, although large price increases are seen with the highest doses of fluvastatin and lovastatin and between the lowest dose of atorvastatin and all other doses of the drug. The cost difference between brand and generic alternatives during the coverage gap varied from $\$ 18.52$ to $\$ 78.89$. Brand-name statins were estimated to be less expensive during the 2020 coverage gap than the 2011 initial coverage copay/coinsurance amounts.

\section{TABLE 4 PPIs: Average (SD) Costs of Brand- Name Medications and Suggested Generic Treatment Alternatives Under 2011 California PDPs}

\begin{tabular}{|c|c|c|c|}
\hline Druga $^{a}$ & & Low Dose & High Dose \\
\hline \multirow{5}{*}{$\begin{array}{l}\text { Dexlansoprazole } \\
(n=24)\end{array}$} & Dose & $30 \mathrm{mg}$ & $60 \mathrm{mg}$ \\
\hline & Total drug cost $(\$)$ & $129.14 \quad(4.07)$ & $129.14 \quad(4.07)$ \\
\hline & Initial coverage $(\$)$ & $56.86(24.21)$ & $56.86(24.21)$ \\
\hline & Coverage gap $(\$)$ & $65.43 \quad(2.28)$ & $65.03 \quad(3.29)$ \\
\hline & 2020 gap $(\$)$ & $32.28 \quad(1.02)$ & $32.28 \quad(1.02)$ \\
\hline \multirow{5}{*}{$\begin{array}{l}\text { Esomeprazole } \\
(n=22)\end{array}$} & Dose & $20 \mathrm{mg}$ & $40 \mathrm{mg}$ \\
\hline & Total drug cost $(\$)$ & $183.98 \quad(8.35)$ & $183.98 \quad(8.35)$ \\
\hline & Initial coverage $(\$)$ & $(6.74)$ & 41.09 \\
\hline & Coverage gap (\$) & $(4.42)$ & 92.80 \\
\hline & 2020 gap $(\$)$ & $46.00 \quad(2.09)$ & $46.00 \quad(2.09)$ \\
\hline \multirow{5}{*}{$\begin{array}{l}\text { Lansoprazole } \\
(n=19)\end{array}$} & Dose & $15 \mathrm{mg}$ & $30 \mathrm{mg}$ \\
\hline & Total drug cost $(\$)$ & $78.26(16.39)$ & $74.52(12.92)$ \\
\hline & Initial coverage $(\$)$ & $24.38 \quad(17.93)$ & $24.35 \quad(17.95)$ \\
\hline & Coverage gap $(\$)$ & $69.54(21.79)$ & $66.04(18.91)$ \\
\hline & 2020 gap $(\$)$ & $19.56 \quad(4.10)$ & $18.63 \quad(3.23)$ \\
\hline \multirow{5}{*}{$\begin{array}{l}\text { Omeprazole } \\
(\mathrm{n}=28)\end{array}$} & Dose & $20 \mathrm{mg}$ & $40 \mathrm{mg}$ \\
\hline & Total drug cost $(\$)$ & $25.24(21.30)$ & $29.27 \quad(24.25)$ \\
\hline & Initial coverage $(\$)$ & $5.23 \quad(4.44)$ & $5.54 \quad(4.39)$ \\
\hline & Coverage gap $(\$)$ & $20.56(21.18)$ & $23.83(23.83)$ \\
\hline & 2020 gap $(\$)$ & $6.31 \quad(5.33)$ & $7.32 \quad(6.06)$ \\
\hline \multirow{5}{*}{$\begin{array}{l}\text { Pantoprazole } \\
(n=14)\end{array}$} & Dose & $20 \mathrm{mg}$ & $40 \mathrm{mg}$ \\
\hline & Total drug cost $(\$)$ & $69.54(35.74)$ & $68.48 \quad(34.49)$ \\
\hline & Initial coverage $(\$)$ & $22.08(23.34)$ & $22.04(23.33)$ \\
\hline & Coverage gap $(\$)$ & $58.65(35.77)$ & $58.04(34.86)$ \\
\hline & 2020 gap $(\$)$ & $17.39 \quad(8.93)$ & $17.12 \quad(8.62)$ \\
\hline \multirow{5}{*}{$\begin{array}{l}\text { Rabeprazole } \\
(n=2)\end{array}$} & Dose & & $20 \mathrm{mg}$ \\
\hline & Total drug cost $(\$)$ & & $209.86 \quad(0)$ \\
\hline & Initial coverage $(\$)$ & & $92.34(32.65)$ \\
\hline & Coverage gap $(\$)$ & & $106.18 \quad(0)$ \\
\hline & 2020 gap $(\$)$ & & 52.47 \\
\hline \multicolumn{4}{|c|}{$\begin{array}{l}\text { an indicates number of PDPs with medication on plan formulary. } \\
\text { bIndicates drug was available brand only at the time of data pull. } \\
\text { mg=milligram; } P D P=\text { prescription drug plan; } P P I=\text { proton pump inhibitors; } \\
\text { SD=standard deviation. }\end{array}$} \\
\hline
\end{tabular}

At the time of this study, atorvastatin was only available as a brand-name drug.

\section{Discussion}

Our study revealed that the cost disparity between brand and generic medications filled prior to the gap is decreased considerably once the beneficiary reaches the coverage gap. In 2011, 7.9\% of Medicare beneficiaries reached the coverage gap, receiving over $\$ 2.3$ billion collectively in coverage gap discounts. ${ }^{15}$ The absolute beneficiary cost difference between brand-name medications and generic alternatives should continue to shrink each year (plateauing in 2020), as an increasing percentage of a beneficiary's formulary covered medication costs are subsidized during the gap. Beneficiary OOP gap costs for 2020 were estimated in this study and indicated that 
Cost Variability of Suggested Generic Treatment Alternatives Under the Medicare Part D Benefit

\section{TABLE 5 Statins: Average (SD) Costs of Brand-Name Medications and Suggested} Generic Treatment Alternatives Under 2011 California PDPs

\begin{tabular}{|c|c|c|c|c|c|c|c|c|}
\hline \multirow[b]{2}{*}{ Druga } & & \multicolumn{7}{|c|}{$\%$ LDL decrease $^{b}$} \\
\hline & & $15 \%-19 \%$ & $20 \%-30 \%$ & $31 \%-39 \%$ & $40 \%-45 \%$ & $46 \%-49 \%$ & $50 \%-54 \%$ & $55 \%+$ \\
\hline \multirow{5}{*}{$\begin{array}{l}\text { Fluvastatinc } \\
(\mathrm{n}=10)\end{array}$} & Dose & $20 \mathrm{mg}$ & $40 \mathrm{mg}$ & $80 \mathrm{mg}$ & & & & \\
\hline & Total drug cost $(\$)$ & $98.15 \quad(4.69)$ & $98.15 \quad(4.69)$ & $190.99 \quad(6.65)$ & & & & \\
\hline & Initial coverage $(\$)$ & $55.95(24.82)$ & $55.95(24.82)$ & $63.94(26.49)$ & & & & \\
\hline & Coverage gap $(\$)$ & $50.03 \quad(2.28)$ & $50.03 \quad(2.28)$ & $96.44 \quad(3.42)$ & & & & \\
\hline & 2020 gap $(\$)$ & $24.54 \quad(1.17)$ & $24.54 \quad(1.17)$ & $47.75 \quad(1.66)$ & & & & \\
\hline \multirow{5}{*}{$\begin{array}{l}\text { Lovastatin } \\
(10 \mathrm{mg}: \mathrm{n}=23 \text {; } \\
20 \mathrm{mg} \text { and } \\
40 \mathrm{mg}: \mathrm{n}=25 \\
80 \mathrm{mg}: \mathrm{n}=26)\end{array}$} & Dose & $10 \mathrm{mg}$ & $20 \mathrm{mg}$ & $40 \mathrm{mg}$ & $\begin{array}{c}80 \mathrm{mg} \\
(40 \mathrm{mg} \text { BID })\end{array}$ & & & \\
\hline & Total drug cost $(\$)$ & $13.56 \quad(7.08)$ & $17.08(13.28)$ & $24.62(23.64)$ & $62.60(71.06)$ & & & \\
\hline & Initial coverage $(\$)$ & $4.09 \quad(3.05)$ & $4.41 \quad(3.04)$ & $4.71 \quad(3.00)$ & $5.29 \quad(3.53)$ & & & \\
\hline & Coverage gap (\$) & $11.26 \quad(7.54)$ & $14.32(13.14)$ & $19.45(21.68)$ & $52.30(69.26)$ & & & \\
\hline & 2020 gap $(\$)$ & $3.39 \quad(1.77)$ & $4.27 \quad(3.32)$ & $6.15 \quad(5.91)$ & $15.65(17.77)$ & & & \\
\hline \multirow{5}{*}{$\begin{array}{l}\text { Pravastatin } \\
(10 \mathrm{mg} \text { and } \\
20 \mathrm{mg}: \mathrm{n}=28 ; \\
40 \mathrm{mg} \text { and } \\
80 \mathrm{mg}: \mathrm{n}=27)\end{array}$} & Dose & $10 \mathrm{mg}$ & $20 \mathrm{mg}$ & $40 \mathrm{mg}$ & $80 \mathrm{mg}$ & & & \\
\hline & Total drug cost $(\$)$ & $17.99(17.12)$ & $17.90(17.50)$ & $22.87(26.29)$ & $31.36(24.19)$ & & & \\
\hline & Initial coverage $(\$)$ & $4.35 \quad(2.96)$ & $4.33 \quad(2.96)$ & $4.38 \quad(2.94)$ & $4.75 \quad(2.99)$ & & & \\
\hline & Coverage gap $(\$)$ & $15.01(16.75)$ & $15.03(16.98)$ & $19.07(25.48)$ & $24.29(25.00)$ & & & \\
\hline & 2020 gap $(\$)$ & $4.50 \quad(4.28)$ & $4.47 \quad(4.37)$ & $\begin{array}{ll}5.72 & (6.57) \\
\end{array}$ & $7.84 \quad(6.05)$ & & & \\
\hline \multirow{5}{*}{$\begin{array}{l}\text { Simvastatin } \\
(5 \mathrm{mg}, 20 \mathrm{mg} \\
40 \mathrm{mg}: \mathrm{n}=26 \\
10 \mathrm{mg}: \mathrm{n}=24 \\
80 \mathrm{mg}: \mathrm{n}=27)\end{array}$} & Dose & $5 \mathrm{mg}$ & $10 \mathrm{mg}$ & $20 \mathrm{mg}$ & $40 \mathrm{mg}$ & $80 \mathrm{mg}$ & & \\
\hline & Total drug cost $(\$)$ & $16.26(11.69)$ & $17.65(15.87)$ & $22.01(28.19)$ & $22.22(28.04)$ & $22.67(27.41)$ & & \\
\hline & Initial coverage $(\$)$ & $4.01 \quad(2.72)$ & $3.73 \quad(2.76)$ & $3.95 \quad(2.80)$ & $4.08 \quad(2.74)$ & $4.32 \quad(2.88)$ & & \\
\hline & Coverage gap (\$) & $12.78(11.72)$ & $14.35(15.69)$ & $18.28(27.16)$ & $18.30(27.09)$ & $18.65(26.56)$ & & \\
\hline & 2020 gap $(\$)$ & $4.07 \quad(2.92)$ & \begin{tabular}{ll|}
4.41 & $(3.97)$ \\
\end{tabular} & $5.50 \quad(7.05)$ & $5.56 \quad(7.01)$ & $5.67 \quad(6.85)$ & & \\
\hline \multirow{5}{*}{$\begin{array}{l}\text { Atorvastatin }{ }^{\mathrm{c}} \\
(10 \mathrm{mg}, 40 \mathrm{mg} \text {, } \\
80 \mathrm{mg}: \mathrm{n}=23 \\
20 \mathrm{mg}: \mathrm{n}=22)\end{array}$} & Dose & & & $10 \mathrm{mg}$ & $20 \mathrm{mg}$ & $40 \mathrm{mg}$ & $80 \mathrm{mg}$ & \\
\hline & Total drug cost $(\$)$ & & & $112.18(14.86)$ & $153.49 \quad(6.31)$ & $153.38 \quad(6.19)$ & $153.38 \quad(6.19)$ & \\
\hline & Initial coverage $(\$)$ & & & $36.67(16.10)$ & $40.09(17.77)$ & $39.66(17.48)$ & $39.66(17.48)$ & \\
\hline & Coverage gap (\$) & & & $57.06 \quad(7.59)$ & $77.62 \quad(3.27)$ & $77.57 \quad(3.21)$ & $77.57 \quad(3.21)$ & \\
\hline & 2020 gap $(\$)$ & & & $28.05 \quad(3.72)$ & $38.37 \quad(1.58)$ & $38.35 \quad(1.55)$ & $38.35 \quad(1.55)$ & \\
\hline \multirow{5}{*}{$\begin{array}{l}\text { Rosuvastatin }{ }^{\mathrm{c}} \\
(5 \mathrm{mg}, 10 \mathrm{mg} \\
20 \mathrm{mg}: \mathrm{n}=23 \\
40 \mathrm{mg}: \mathrm{n}=25 \text { ) }\end{array}$} & Dose & & & & $5 \mathrm{mg}$ & $10 \mathrm{mg}$ & $20 \mathrm{mg}$ & $40 \mathrm{mg}$ \\
\hline & Total drug cost $(\$)$ & & & & $139.53 \quad(6.07)$ & $139.53 \quad(6.07)$ & $139.53 \quad(6.07)$ & $139.16 \quad(5.95)$ \\
\hline & Initial coverage $(\$)$ & & & & $39.34(20.87)$ & $39.34(20.87)$ & $39.34(20.87)$ & $38.60(20.20)$ \\
\hline & Coverage gap (\$) & & & & $70.82 \quad(3.08)$ & 70.82 (3.08) & $70.82 \quad(3.08)$ & $70.63 \quad(3.18)$ \\
\hline & 2020 gap $(\$)$ & & & & $34.88 \quad(1.52)$ & $34.88 \quad(1.52)$ & $34.88 \quad(1.52)$ & $34.79 \quad(1.49)$ \\
\hline
\end{tabular}

$a_{n}$ indicates number of PDPs with medication on plan formulary.

${ }^{b}$ LDL decrease based on Medicare Plan Finder Tool equivalency tables and package insert data.

'Indicates drug was available brand only at the time of data pull.

$B I D=$ twice daily; $L D L=$ low-density lipoprotein; $m g=$ milligram; $P D P=$ prescription drug plan; $S D=$ standard deviation; statin=HMG-CoA reductase inhibitor

generics will still remain less expensive than brand-name medications; however, copay/coinsurance amounts in the 2020 coverage gap were estimated to be lower than current OOP costs during the initial coverage phase (generally the least expensive coverage level of the Medicare Part D benefit).

As expected, the cost difference between brand-name medications and equipotent doses of suggested generic treatment alternatives was far less when filled during the gap. However, unexpectedly, we also found that in 1 instance filling a brandname medication (Dexilant [dexlansoprazole]) would have been less expensive than filling a suggested generic treatment alternative (lansoprazole) during the gap across the examined PDPs. This finding may be explained by the late entry of dexlansoprazole to the market and the competitive pricing by its manufacturer to help increase market share. Another possible contributor to this finding is that generic lansoprazole became available in late 2009, and the cost disparity between the brand-name medication (Prevacid) and its generic alternative (lansoprazole) may have been at its lowest level at that point in time.

The decrease in cost disparity between brand-name medications and suggested generic treatment alternatives may change beneficiary behavior. As previous research has suggested, patients are willing to pay nominally more for brand-name medications when a cheaper generic alternative is available. ${ }^{11}$ Based on these findings, one could infer that upon reaching the gap, there may be less financial pressure to switch from a higher cost brand-name medication to a less expensive 
suggested generic treatment alternative from the same medication class. The result of such behavior might be increased and unnecessary medications costs that are paid for by private plan sponsors and/or the Medicare program. This behavior may be enhanced by the low OOP costs observed in the estimated 2020 coverage gap costs, which were lower than the average initial coverage copay/coinsurance amounts for all brand-name drugs included in this study, except esomeprazole. This would also increase the cost to the PDP, since the plan will be responsible for an equivalent amount (25\% of brand-name medications) during the coverage gap in 2020.

The estimated 2020 coverage gap costs presented in this study (Tables 2-5) are the costs to both the beneficiary and the PDP. In 2013 and 2014, PDPs become responsible for 2.5\% of total brand-name drug costs in the coverage gap with a rapid increase to $25 \%$ by 2020 (Table 1), indicating a financial incentive for plans to keep beneficiaries from reaching the coverage gap. This is counter to the lower beneficiary OOP costs during the 2020 coverage gap as compared with the 2011 copay/coinsurance amounts in the initial coverage phase. This opposing financial incentive may lead to increased utilization of brandname medications during the gap and increased PDP costs if patients do not switch to suggested generic alternatives. While many of the brand-name medications examined in this study have already gone generic at the time of publication, and many more will by 2020, the medications included in this study are a small sample of the multitude of drug classes that will continue to have brand-name only medications. As has been observed with premiums in the wake of the Patient Protection and Affordable Care Act, the effects of copay/coinsurance subsidization during the coverage gap may cause an increase in beneficiary OOP costs during the initial coverage phase to allow for PDPs to recoup the increased expense during the coverage gap.

Future studies examining the fill rates of brand-name medications and suggested generic treatment alternatives before, during, and after the coverage gap would enable assessment as to whether beneficiary and/or prescriber behavior changes during each of these different phases of the Medicare benefit. Using a claims database to retrospectively examine Medicare beneficiary adherence and medication switching in response to price changes and the impact of generic substitutions would allow for the examination of the effects on health care reform policies.

\section{Limitations}

First, only 28 of the 33 California PDPs available in 2011 were included in data collection due to lack of availability of plan information for the other 5 plans on the Medicare website. Second, the collected data were specific for the changes in Medicare being implemented in 2011. Therefore, it is possible that the results may differ in subsequent years based on annual changes that occur to the Medicare benefit and changes in drug costs. Third, the cost data collected were specific for PDPs offered in California and may not be generalizable nationally. Fourth, the estimated coverage gap costs for 2020 do not take into account unknown and incalculable changes to brand and generic drug prices and are calculated based on 2011 total drug costs. We recommend that future studies be conducted to see if our results are replicable in the other 33 Medicare regions. Lastly, this study does not account for possible discount programs (e.g., $\$ 4$ generics) that beneficiaries can utilize to reduce OOP costs outside of their PDP benefits.

These limitations notwithstanding, this is the first study known to examine the cost difference between brand-name medications and suggested generic treatment alternatives during the coverage gap and to estimate the costs to beneficiaries and Part D plans when the full discount is implemented in 2020 .

\section{Conclusions}

Medicare beneficiaries can realize significant costs savings by taking suggested generic treatment alternatives prior to the coverage gap. Additionally, due to larger discounts on brand medications, the potential dollar savings by taking suggested generic treatment alternatives during the gap is less financially compelling from a beneficiary's perspective, especially as the coverage gap subsidy increases in future years. While beneficiary copayment increases indirectly correlate with medication adherence rates, current policy and practices may incentivize brand-name medication use during the coverage gap, placing PDPs at a financial disadvantage when suggested generic treatment alternative medications are available.

\section{Authors}

RAJUL A. PATEL, PharmD, PhD, is Associate Professor; MARK P. WALBERG, PharmD, PhD, is Assistant Professor; and SUZANNE M. GALAL, PharmD, is Assistant Professor, Department of Pharmacy Practice, University of the Pacific Thomas J. Long School of Pharmacy and Health Sciences, Stockton, California. JOSEPH A. WOELFEL, RPh, PhD, is Associate Professor and Vice Chair, Department of Pharmacy Practice, and Director of Pharmaceutical Care Clinics, and SIAN M. CARR-LOPEZ, PharmD, is Professor, Department of Pharmacy Practice, and Assistant Dean of Experiential Programs, University of the Pacific Thomas J. Long School of Pharmacy and Health Sciences, Stockton, California. EMILY TONG, PharmD, is Clinical Pharmacist, Cigna HealthSpring, Kingwood, Texas; FLORENCE TAN, PharmD, is Clinical Pharmacist, Comprehensive Pharmacy Services, Stockton, California; and ASHLEY E. RUMMEL, PharmD, is Clinical Pharmacist, Sutter Tracy Community Hospital, Tracy, California.

AUTHOR CORRESPONDENCE: Rajul A. Patel, PharmD, PhD, University of the Pacific Thomas J. Long School of Pharmacy and Health Sciences, 751 Brookside Rd., Stockton, CA 95211.

Tel.: 209.946.3151; Fax: 209.946.2402; E-mail: rpatel@pacific.edu. 


\section{DISCLOSURES}

Patel reports no conflicts of interest. He received a grant from the United Way Community Impact Fund to provide some of the services included in the community outreach that was used to collect data for this study. The other authors report no relevant conflicts or financial activities.

Concept and design were primarily contributed by Patel, along with Walberg, Rummel, Tan, and Tong. Rummel, Tong, and Tan were responsible for data collection, with assistance from Walberg, Woelfel, Galal, and Patel. Date interpretation was primarily the responsibility of Patel and Walberg, with assistance from Carr-Lopez and Galal. The manuscript was written by Tan, Patel, Rummel, and Tong, with assistance from Woelfel, Carr-Lopez, and Galal, and was revised primarily by Walberg and Patel, with assistance from the other authors.

\section{REFERENCES}

1. Duru OK, Mangione CM, Hsu J, et al. Generic-only drug coverage in the Medicare Part D gap and effect on medication cost-cutting behaviors for patients with diabetes mellitus: the translating research into action for diabetes study. J Am Geriatr Soc. 2010;58(5):822-28.

2. Taira DA, Wong KS, Frech-Tamas F, Chung RS. Copayment level and compliance with antihypertensive medication: analysis and policy implications for managed care. Am J Manag Care. 2006;12(11):678-83. Available at: http://www.ajmc.com/pubMed.php?pii=3217. Accessed November 19, 2013.

3. Gibson TB, Mark TL, Axelsen K, Baser O, Rublee DA, McGuigan KA. Impact of statin copayments on adherence and medical care utilization and expenditures. Am J Manag Care. 2006;12(Spec no.):SP11-19.

4. Maciejewski ML, Bryson CL, Perkins M, et al. Increasing copayments and adherence to diabetes, hypertension, and hyperlipidemic medications. Am J Manag Care. 2010;16(1):e20-34. Available at: http://www.ajmc.com/pubMed. php?pii=12556. Accessed November 19, 2013.

5. Polinski JM, Kilabuk E, Schneeweiss S, Brennan T, Shrank WH. Changes in drug use and out-of-pocket costs associated with Medicare Part D implementation: a systematic review. J Am Geriatr Soc. 2010;58(9):1764-79. Available at: http://www.ncbi.nlm.nih.gov/pmc/articles/PMC2946375/pdf/ nihms199782.pdf. Accessed November 19, 2013.
6. Centers for Medicare \& Medicaid Services. Bridging the coverage gap in 2011. Revised January 2011. Available at: http://www.medicare.gov/ Publications/Pubs/pdf/11213.pdf. Accessed November 19, 2013.

7. Sun SX, Lee KY. The Medicare Part D doughnut hole: effect on pharmacy utilization. Manag Care Interface. 2007;20(9):51-55,59.

8. Polinski JM, Maclure M, Marshall B, et al. Does knowledge of medication prices predict physicians' support for cost effective prescribing policies. Can J Clin Pharmacol. 2008;15(2):e286-94.

9. Wilson IB, Schoen C, Neuman P, et al. Physician-patient communication about prescription medication nonadherence: a 50-state study of America's seniors. J Gen Intern Med. 2007;22(1):6-12. Available at: http://www.ncbi. nlm.nih.gov/pmc/articles/PMC1824770/pdf/11606_2006_Article_93.pdf. Accessed November 19, 2013.

10. Piette JD, Heisler M, Wagner TH. Cost-related medication underuse: do patients with chronic illnesses tell their doctors? Arch Intern Med. 2004;164(16):1749-55. Available at: http://archinte.jamanetwork.com/article. aspx?articleid=217324. Accessed November 19, 2013.

11. Nair KV, Ganther JM, Valuck RJ, McCollum MM, Lewis SJ. Impact of multi-tiered pharmacy benefits on attitudes of plan members with chronic disease states. J Manag Care Pharm. 2002;8(6):477-91. Available at: http:// www.amcp.org/data/jmcp/Research-477-491.pdf.

12. Briesacher BA, Andrade SE, Fouayzi H, Chan KA. Medication adherence and use of generic drug therapies. Am J Manag Care. 2009;15(7):450-56. Available at: http://www.ncbi.nlm.nih.gov/pmc/articles/PMC2918380/pdf/ nihms221351.pdf. Accessed November 19, 2013.

13. Cahill JA. Medicare Part D coverage gap discount program beginning in 2011. J Manag Care Pharm. 2010;16(5):367-68. Available at: http://amcp.org/ WorkArea/DownloadAsset.aspx?id=8345.

14. Centers for Medicare \& Medicaid Services. Closing the coverage gapMedicare prescription drugs are becoming more affordable. Revised May 2013. Available at: http://www.medicare.gov/Publications/Pubs/pdf/11493. pdf. Accessed November 19, 2013.

15. Centers for Medicare $\&$ Medicaid Services. Coverage gap discount program. July 6, 2012. Available at: https://www.cms.gov/Medicare/MedicareAdvantage/Plan-Payment/CGDP.html. Accessed January 2, 2014. 